\title{
HUBUNGAN TRY OUT DENGAN TINGKAT KELULUSAN UJI KOMPETENSI PERAWAT DI UNIVERSITAS SEMBILANBELAS NOVEMBER KOLAKA
}

\author{
Heriviyatno Julika Siagian', Arman Sagita²
}

1) Program studi keperawatan Program Diploma Tiga, Fakultas sains dan teknologiUniversitas Sembilanbelas November, Kab. Kolaka, Sulawesi Tenggara

e-mail: heriviyatno.j.siagian@gmail.com

\begin{abstract}
ABSTRAK
Uji Kompetensi adalah proses pengukuran pengetahuan, keterampilan, dan perilaku peserta didik pada perguruan tinggi yang menyelenggarakan pendidikan tinggi bidang Kesehatan. Data yang diperoleh dari hasil pengumuman uji kompetensi perawat di Kampus Akper Pemkab Kolaka dari bulan Juli 2017 periode IX pendaftar 18 orang yang lulus 2 orang (11\%) dan tidak lulus 16 orang (89\%). Tujuan dari penelitian ini adalah untuk mengetahui faktor - faktor yang berhubungan dengan tingkat kelulusan uji kompetensi perawat di Universitas Sembilanbelas November Kolaka. Jenis penelitian ini adalah adalah Analitik dengan menggunakan desain Cross Sectional Study, populasi dalam penelitian ini adalah 80 orang dan sampel berjumlah 67 orang dengan menggunakan tehnik Simple Random Sampling. Metode analisis menggunakan uji Spearman - Rank. Hasil Uji statistik menunjukkan ada hubungan antara variabel try out dengan hasil $P$-Value $=0,013$ dan coefisien corelation $=0,301$ dengan tingkat kelulusan uji kompetensi. Diharapkan bagi institusi perguruan tinggi kesehatan agar lebih memperhatikan faktor - faktor yang memiliki hubungan erat dengan tingkat kelulusan uji kompetensi perawat yaitu salah satunya dengan cara kegiatan try out mahasiswa diperbanyak, dan lebih diefektifan lagi gaya belajar mahasiswa sehingga dapat dijadikan pedoman untuk meningkatkan mutu tingkat kelulusan uji kompetensi perawat.
\end{abstract}

Kata Kunci $\quad$ : Try Out, Tingkat Kelulusan, ujian kompetensi

\section{ABSTRACT}

Competency Test is a process of measuring students' knowledge, skills, and attitude in universities that organize higher education in Health. Data obtained from the results of the nurse competency test at Sembilanbelas November University in Kolaka from July 2017 period IX showed that 2 of 18 (11\%) registered participants passed the test and 16 others (89\%) did not pass it. The purpose of this study was to determine the factors correlated to the graduation level of the competency test at Sembilanbelas November University in Kolaka. This type of this research was Analytic using the design of Cross Sectional Study. The population of this study was 80 people where 67 of them were taken as sample using the Simple Random Sampling technique which was then analyzed using Spearman-Rank test method. The results of Statistical tests showed that there is a correlation between the try out variable and the gradution of competency test (Pvalue $=0.013$ and correlation coefficient $=0.301$ ), there is no correlation between Grade Point Average variable and the graduation of competency test (Pvalue $=0.349$ and correlation coefficient $=0.116$ ), and there is a correlation between learning style variable and the graduation of competency test (Pvalue $=0,000$ and correlation coefficient $=0.517$ ). It is expected that nursing colleges pay more attention to factors that have a close correlation with the graduation level of nursing competency test. One of them is by icreasing the number of try out for students, and making student learning styles effective in order to improve the graduation level of the nurse competency test.

\section{Key words : Try Out, GPA, Learning Style, Graduation Level PENDAHULUAN}

Perawat merupakan bagian dari telah lulus pendidikan perawat baik di dalam tenaga kesehatan yang harus memiliki maupun di luar negeri sesuai dengan kompetensi dalam menjalankan pelayanan ketentuan peraturan perundang-undangan kesehatan. Perawat adalah seseorang yang yang berlaku [5]. Perawat sebagai tenaga 
professional bertanggung jawab dan

berwenang memberikan pelayanan

keperawatan secara mandiri dan

berkolaborasi dengan tenaga kesehatan lain sesuai dengan kewenangannya, terutama terkait dengan lingkup praktik dan wewenang perawat [1].

Peningkatan kualitas pendidikan tenaga kesehatan adalah salah satu langkah strategis untuk meningkatkan ketersediaan tenaga kesehatan berkualitas dan memiliki kompetensi yang relevan untuk menjalankan sistem pelayanan kesehatan.Salah satu upaya yang dilakukan untuk mendorong percepatan peningkatan dan pemerataan kualitas pendidikan kesehatan adalah dengan meningkatkan kendali mutu lulusan pendidikan yang kompeten dan memperoleh sertifikat kompetensi, perawat harus mengikuti Uji Kompetensi [2].

Uji Kompetensi adalah proses pengukuran pengetahuan, keterampilan, dan perilaku peserta didik pada perguruan tinggi yang menyelenggarakan pendidikan tinggi bidang Kesehatan. Ujian ini ditujukan untuk mencapai standar kompetensi lulusan yang memenuhi standar kompetensi kerja. Uji Kompetensi Nasional dapat dijadikan sebagai bagian dari penjaminan mutu pendidikan [3].

DIKTI memaparkan bahwa hasil uji kompetensi yang telah dilakukan pada mahasiswa DIII keperawatan dan Ners masih belum memuaskan, sehingga masih diperlukan perbaikan pada sistem pendidikan keperawatan. Oleh karena itu, tanggal 18 Juni 2014 Kementerian Pendidikan dan Kebudayaan Direktorat Jenderal Pendidikan Tinggi mengeluarkan surat edaran nomor 529/E.E3/DT/2014 tentang Status Uji Kompetensi bagi Mahasiswa Program Studi DIII Kebidanan, DIII Keperawatan dan Ners yang berisi tentang belum digunakannya uji kompetensi untuk menentukan kelulusan atau sebagai exit exam [4]
Data hasil pengumuman hasil Uji

Kompetensi mahasiswa yang berlokasi di Kampus Akper Pemkab Kolaka dari periode 3 tahun terakhir menunjukkan bahwa jumlah peserta Uji Kompetensi pada Juni 2015 periode ke IV sebanyak 65 orang, dengan jumlah kelulusan sebanyak 7 orang (11\%) dan yang tidak lulus sebanyak 58 orang (89\%), dan jumlah peserta Uji Kompetensi pada September 2015 periode ke $V$ sebanyak 138, dengan jumlah kelulusan sebanyak 78 orang $(57 \%)$ dan yang tidak lulus sebanyak 60 orang (43\%). Pada Mei 2016 periode ke VI jumlah pendaftar Uji Kompetensi sebanyak 54 orang, dengan jumlah kelulusan menunjukkan penurunan yaitu sebanyak 5 orang (9\%) dan yang tidak lulus sebanyak 49 orang (91\%). Pada Oktober 2016 periode ke VII jumlah pendaftar Uji Kompetensi sebanyak 126 orang, dengan jumlah kelulusan sebanyak 61 orang $(48 \%)$ dan yang tidak lulus sebanyak 65 orang (52\%). Pada Maret 2017 periode ke VIII jumlah pendaftar Uji Kompetensi sebanyak 58 orang, dengan jumlah kelulusan sebanyak 10 orang (17\%) dan yang tidak lulus sebanyak 48 orang (83\%). Pada Juli 2017 periode ke IX jumlah pendaftar Uji Kompetensi sebanyak 18 orang, dengan jumlah kelulusan kembali lagi mengalami penurunan yang sangat drastis yaitu sebanyak 2 orang (11\%) dan yang tidak lulus sebanyak 16 orang (89\%), sedangkan pada Oktober 2017 periode ke $X$ jumlah pendaftar Uji Kompetensi sebanyak 80 orang, dengan jumlah kelulusan sebanyak 54 orang (68\%) dan yang tidak lulus sebanyak 26 orang (33\%). Hal ini menunjukkan angka pencapaian yang sangat rendah sekali sehingga dapat menjadi masalah yang perioritas terhadap kualitas lulusan.

Berbagai upaya dicoba untuk
dilakukan agar dapat meningkatkan persentase kelulusan ujian kompetensi. Salah satu upaya yang efektif dalam rangka meningkatkan kelulusan adalah dengan 
melakukan Try Out atau latihan sebelum menghadapi Uji Kompetensi agar bisa mengukur sejauh mana kemampuan peserta mahasiswa perawat dalam mempersiapkan ujian kompetensi.

Tryout merupakan suatu mekanisme yang digunakan sebagai sebuah latihan bagi siswa sebelum melaksanakan ujian yang sesungguhnya. Try out hanyalah sebagai media untuk berlatih soal -soal. Semakin banyak berlatih, maka peserta didik akan semakin siap untuk menghadapinya.

Dalam studi yang dilakukan oleh Refrensi [6] menyatakan bahwa ada hubungan yang cukup signifikan anatara Try Out dengan tingkat kelulusan ujian kompetensi. Try Out memberikan kesempatan kepada mahasiswa untuk mengeksplorasi bentuk-bentuk soal yang diujikan dalam ujian kompetensi, karena soalsoal latihan yang diberikan sangat mirip dengan soal pada ujian kompetensi. Mahasiswa juga lebih siap secara mental dalam menghadapi ujian kompetensi karena sudah familiar dengan bentuk-bentuk soal yang muncul dalam ujian kompetensi [6].

Studi lainnya yang dilakukan pada beberapa Perguruan Tinggi di Jawa Timur didapatkan hasil bahwa persentase kelulusan mahasiswa pada Perguruan Tinggi yang melakukan program Try Out lebih besar di bandingkan Perguruan Tinggi yang tidak melakukan program Try Out [7].

Permasalahan ini harus segera di tindak lanjuti karena secara tidak langsung akan memberikan dampak terhadap kualitas lulusan perawat Indonesia dan tentunya bagi institusi yang bersangkutan . berdasarkan permasalahan maka studi ini dilakukan untuk melihat bagaimana hubungan antara pemecahan masalah dalam hal ini Try Out dengan tingkat kelulusan ujian kompetensi perawat.

\section{METODOLOGI}

Jenis penelitian yang digunakan

dalam penelitian ini adalah Analitik dengan menggunakan desain Cross Sectional Study, untuk melihat hubungan variabel Try Out dengan tingkat kelulusan ujian kompetensi di prodi diploma tiga keperawatan Universitas sembilanbelas November Kolaka.

Penelitian ini dilakukan di Universitas Sembilanbelas November Kolaka pada tanggal 22 Mei sampai dengan 7 Juni Tahun 2018. Populasi dalam penelitian ini adalah semua peserta Uji Kompetensi Periode $X$ tahun 2017 yaitu sebanyak 80 orang peserta. Sampel dalam penelitian ini peserta uji kompetensi yang terpilih menggunakan tehnik Simple Random Sampling berjumlah 67 orang. Instrument yang digunakan dalam penelitian ini adalah kuesioner. Analisis data menggunakan analisis univariat dan analisis bivariat, dan untuk analisis statistic menggunakan uji Spearman Rank dengan taraf signifikasi 0,05 atau $5 \%$.

\section{HASIL DAN PEMBAHASAN}

Distribusi responden berdasarkan jenis kelamin, umur, dan status kerja di Universitas Sembilanbelas November Kolaka terlihat pada tabel sebagai berikut :

Tabel 1 Karakteristik Responden

\begin{tabular}{lcc} 
Karakteristik & $\begin{array}{c}\text { Jumlah } \\
(\mathbf{n = 6 7 )}\end{array}$ & $\begin{array}{c}\text { Persentase } \\
(\%)\end{array}$ \\
\hline Jenis Kelamin & & \\
Laki-laki & 16 & 23,9 \\
Perempuan & 51 & 76,1 \\
Umur & & \\
$20-25$ & 49 & 73,1 \\
$26-30$ & 18 & 26,9 \\
& & \\
Status Kerja & & \\
Sudah bekerja & 42 & 62,7 \\
Belum bekerja & 25 & 37,3
\end{tabular}

Sumber : Data primer, diolah bulan Juni 2018

\section{Berdasarkan tabel di atas}

berdasarkan jenis kelamin dari 67 responden (100\%) terdapat 16 responden (23,9\%) dengan jenis kelamin pria dan 51 responden $(5,4 \%)$ dengan jenis kelamin wanita. Berdasarkan umur menunjukkan responden terbesar terdapat pada kelompok umur 20-25 
tahunsebanyak 49 responden $(73,1 \%)$ sedangkan responden terkecil terdapat pada kelompok umur 26 - 30 tahun sebanyak 18 responden (26,9\%). Dan berdasarkan status bekerja didapatkan responden yang sudah bekerjase banyak 42 responden $(62,7 \%)$ sedangkan responden yang belum bekerja sebanyak 25 responden (37,3\%).

Tabel 2 Distribusi responden berdasarkan dengan pelaksanaan try out

\begin{tabular}{lcc}
\hline $\begin{array}{l}\text { Pelaksanaan } \\
\text { Try Out }\end{array}$ & $\begin{array}{c}\text { Jumlah } \\
\text { (n) }\end{array}$ & $\begin{array}{c}\text { Persentase } \\
\text { (\%) }\end{array}$ \\
\hline $\begin{array}{l}\text { Mengikuti Try } \\
\text { Out }\end{array}$ & 50 & 74,6 \\
$\begin{array}{l}\text { Tidak Mengikuti } \\
\text { Try Out }\end{array}$ & 17 & 25,4 \\
\hline Total & 67 & 100 \\
\hline Sumber : Data primer, diolah bulan Juni 2018
\end{tabular}

Sumber : Data primer, diolah bulan Juni 2018

Berdasarkan hasil analisis univariat menunjukkan bahwa responden yang telah mengikuti pelaksanaan try out sebanyak 50 responden $(74,6 \%)$ dan yang tidak mengikuti pelaksanaan try out sebanyak 17 responden (25,4\%).

Tabel 3 Hubungan Try Out dengan tingkat kelulusan Ujian Kompetensi Perawat

\begin{tabular}{|c|c|c|c|c|c|c|c|c|}
\hline \multirow{2}{*}{$\begin{array}{c}\text { Ting } \\
\text { kat } \\
\text { kelu } \\
\text { lusa } \\
\text { n } \\
\text { UKo } \\
\text { m } \\
\end{array}$} & \multicolumn{2}{|c|}{$\begin{array}{c}\text { Meng } \\
\text { ikuti } \\
\text { Try } \\
\text { Out }\end{array}$} & \multicolumn{2}{|c|}{$\begin{array}{c}\text { Tidak } \\
\text { Meng } \\
\text { ikuti } \\
\text { Try } \\
\text { Out }\end{array}$} & \multicolumn{2}{|c|}{$\begin{array}{c}\text { Tota } \\
\text { I }\end{array}$} & \multirow{2}{*}{$\begin{array}{l}\text { Si } \\
\text { gn } \\
\dot{(2-} \\
\text { tai } \\
\text { le } \\
\text { d) }\end{array}$} & \multirow[t]{2}{*}{$\begin{array}{c}\text { Coefi } \\
\text { sien } \\
\text { Corr } \\
\text { elati } \\
\text { on }\end{array}$} \\
\hline & $\mathbf{N}$ & $\%$ & $\mathbf{N}$ & $\%$ & $\mathbf{n}$ & $\%$ & & \\
\hline $\begin{array}{l}\text { Lulu } \\
\text { s }\end{array}$ & $\begin{array}{l}3 \\
7\end{array}$ & $\begin{array}{l}8 \\
4, \\
1\end{array}$ & 7 & $\begin{array}{l}1 \\
5 \\
9\end{array}$ & $\begin{array}{l}4 \\
4\end{array}$ & $\begin{array}{l}1 \\
0 \\
0\end{array}$ & & \\
\hline $\begin{array}{l}\text { Tida } \\
\mathrm{k} \\
\text { Lulu } \\
\mathrm{s} \\
\end{array}$ & $\begin{array}{l}1 \\
3\end{array}$ & $\begin{array}{l}5 \\
6 \\
5\end{array}$ & $\begin{array}{l}1 \\
0\end{array}$ & $\begin{array}{l}4 \\
3 \\
5\end{array}$ & $\begin{array}{l}2 \\
3\end{array}$ & $\begin{array}{l}1 \\
0 \\
0\end{array}$ & $\begin{array}{c}0 \\
01 \\
3\end{array}$ & 0,301 \\
\hline $\begin{array}{c}\text { Tota } \\
\text { I }\end{array}$ & $\begin{array}{l}5 \\
0\end{array}$ & $\begin{array}{l}7 \\
4 \\
6\end{array}$ & $\begin{array}{l}1 \\
7\end{array}$ & $\begin{array}{l}2 \\
5 \\
4\end{array}$ & $\begin{array}{l}6 \\
7\end{array}$ & $\begin{array}{l}1 \\
0 \\
0\end{array}$ & & \\
\hline
\end{tabular}

Sumber : Data primer, diolah bulan Juni 2018

Dari tabel di atas menunjukkan bahwa dari 67 responden terdapat 44 responden (100\%) yang lulus uji kompetensi, dari 44 responden yang lulus uji kompetensi terdapat 37 responden $(84,1 \%)$ yang pernah mengikuti try out, dan 7 responden (15,9\%) yang tidak pernah mengikuti try out.
Selanjutnya dari 23 responden (100\%)

yang tidak lulus uji kompetensi, terdapat 13 responden(56,5\%) yang pernah mengikuti try out, dan 10 responden (43,5\%) yang tidak pernah mengikuti try out.

Hasil uji statistik diperoleh nilai Sig. (2Tailed) $=0,013$ yang berarti nilai Sig. (2Tailed) $<$ dari nilai $\alpha=0,05$ maka Ha diterima. Maka dapat disimpulkan bahwa ada hubungan antara try out dengan tingkat kelulusan uji kompetensi perawat di Universitas Sembilanbelas November Kolaka. Hasil analisis uji keeratan dengan menggunakan uji spearman rank diperoleh nilai Coefisien Corelation $=0,301$ angka tersebut menunjukkan antara 0,020 - 0,399 demikian dapat diinterprestasikan bahwa try out mempunyai hubungan korelasi yang lemah dengan tingkat kelulusan uji kompetensi perawat di Universitas Sembilanbelas November Kolaka.

Mahasiswa yang telah mengikuti try out akan lebih siap mengerjakan soal ujian karena telah mempunyai gambaran tipe soal serta lebih tenang dalam proses pengerjaannya sehingga hasilnya akan lebih bagus dari pada mahasiswa yang tidak mengikuti try out. Dengan mengikuti try out akan mampu memberikan gambaran mengenai model soal yang akan keluar pada saat ujian kompetensi nasional yang sebenarnya. try out merupakan suatu mekanisme yang digunakan sebagai sebuah latihan bagi mahasiswa sebelum melaksanakan ujian yang sesungguhnya. try out hanyalah sebagai media untuk berlatih soal - soal. Semakin banyak berlatih, maka peserta didik akan semakin siap untuk menghadapinya [6].

Try Out merupakan suatu mekanisme yang digunakan sebagai sebuah latihan sebelum melaksanakan ujian yang sesuangguhnya. try out hanyalah sebagai media untuk berlatih soal-soal. Semakin 
banyak berlatih, maka akan semakin siap untuk menghadapinya.

Berdasarkan hasil penelitian didapatkan bahwa dari 44 responden yang lulus uji kompetensi terdapat 37 responden $(84,1 \%)$ yang pernah mengikuti try out, dan 7 responden (15,9\%) yang tidak pernah mengikuti try out. Dan hasil uji statistik diperoleh nilai Sig. (2-Tailed) $=0,013$ yang berarti nilai Sig. (2-Tailed) $<$ dari nilai $\alpha=0,05$ maka Ha diterima, yang berarti bahwa ada hubungan antara try out dengan tingkat kelulusan uji kompetensi perawat di Universitas Sembilanbelas November Kolaka.

Selanjutnya berdasarkan hasil analisis uji keeratan dengan menggunakan uji spearman rank diperoleh nilai Coefisien Corelation $=0,301$ angka tersebut menunjukkan antara 0,020 - 0,399 demikian dapat diinterprestasikan bahwa try out mempunyai hubungan korelasi yang lemah dengan tingkat kelulusan uji kompetensi Perawat Diploma Tiga di Universitas Sembilanbelas November Kolaka.

Menurut hasil observasi peneliti, hal tersebut disebabkan karena responden memahami model soal dan blueprint uji kompetensi yang diberikan oleh pembimbing dalam pelaksanaan try out sehingga pada saat uji kompetensi dilaksanakan, responden lebih mudah dalam memilih jawaban pada soal uji kompetensi yang sesungguhnya.

Pemerintah saat ini telah menetapkan bahwa lulusan dari pendidikan jenjang diploma tiga keperawatan dipersyaratkan lulus dalam kegiatan uji kompetensi sebagai persyaratan untuk memperoleh surat tanda registrasi (STR). Salah satu upaya yang dapat dilakukan untuk meningkatkan kesiapan lulusan dalam menghadapi ujian kompetensi adalah dengan mengadakan try out. Melalui kegiatan try out yang diselenggarakan diharapkan mampu memberikan pemahaman kepada peserta tentang model soal dan teknis ujian sehingga secara mental dan secara teknis mereka mampu menyiapkan diri dengan lebih baik.

Sejalan dengan penelitian yang dilakukan Anas tentang kemaknaan try out terhadap kelulusan ujian kompetensi pada program D-III keperawatan di Jawa Timur dengan hasil yang menunjukkan bahwa ratarata kelulusan dari kelompok yang mengikuti try out adalah $71,06 \%$ dan kelompok yang tidak mengikuti try out adalah 60,83\%. Hasil ini menunjukkan bahwa ada kecenderungan kelompok yang mengikuti try out mendapatkan hasil yang lebih baik daripada kelompok yang tidak mengikuti try out [7].

\section{KESIMPULAN}

Berdasarkan hasil penelitian, maka dapat disimpulkan bahwa Ada hubungan antara try out dengan kelulusan uji kompetensi perawat di Universitas Sembilanbelas November Kolaka dengan nilai signifikan $P$-Value $=0,013$ dan tingkat hubungan korelasi yang lemah yaitu 0,301 . Saran untuk institusi perguruan tinggi kesehatan diharapkan agar lebih memperhatikan faktor - faktor yang memiliki hubungan erat dengan tingkat kelulusan uji kompetensi perawat. Salah satunya yaitu dengan cara kegiatan try out mahasiswa lebih ditingkatkan lagi serta gaya belajar metode visual lebih diefektifkan lagi sehingga dapat dijadikan pedoman untuk meningkatkan mutu tingkat kelulusan Uji Kompetensi perawat di Universitas Sembilanbelas November Kolaka.

\section{DAFTAR PUSTAKA}

1. Info Datin Pusat Informasidan Data Kementerian Kesehatan RI, (2017) http://www.depkes.go.id/resources/downlo ad/pusdatin/infodatin/infodatin\%20perawa t\%202017.pdf. Di Akses 31 Januari 2018.

2. Notoatmojo, Soekidjo.(2014).Metodologi Penelitian

Kesehatan. Jakarta:RinekaCipta.

3. Anggraeni, Novi.(2013).Gambaran Tingkat Kecemasan Pada Mahasiswa 


Tingkat D III Keperawatan Dalam

Menghadapi Uji Kompetensi,

4. Masfuri. (2015) Panduan Pelaksanaan Uji Kompetensi Bagi Mahasiswa Program Diploma III Kebidanan, Diploma III Keperawatan, dan Profesi Ners Periode September 2015

5. Arikunto, S (2002). Prosedur Penelitian, Suatu Pendekatan Praktek, Jakarta: PT Rineka Cipta.
6. Abdillah, Alvin. (2016). Analisis FaktorFaktor Yang Mempengaruhi Kelulusan Uji Kompetensi Ners Indonesia. Vol. 2 No. 2, hal. 373-380.

7. Peraturan Menteri Kesehatan Republik Indonesia Nomor 1796/Menkes/Per/VIII/2011 Tentang Registrasi Tenaga Kesehatan. 